\title{
Exhaled Nitric Oxide Measurement in Pediatric Asthma
}

\author{
PULMONOLOGIST'SPERSPECTIVE \\ RANJAN SURI \\ Pediatric Respiratory Consultant, Respiratory Unit, Great Ormond Street Hospital, and Portex Unit, UCL Institute of Child Health, \\ London, United Kingdom.ranjan.suri@gosh.nhs.uk
}

$\mathrm{N}$ itric oxide (NO) is a biological mediator produced by NO synthase (NOS) in airway epithelial cells, which diffuses into the airway lumen. In the lungs, NO determines smooth muscle relaxation, affects ciliary beat frequency, mucus secretion and plasma exudation, and is involved in inflammation and cell-mediated immunity processes [1]. Measurement of fractional exhaled NO (FENO) requires a series of continuous expiratory manoeuvres using an incentive device. However, the role of measuring FENO as a non-invasive biomarker to optimize asthma management in children is hotly debated.

Chronic airway inflammation is an important feature of asthma. FENO levels are increased in patients with asthma as a result of induction of NOS-2 by proinflammatory cytokines. Elevated FENO levels have been shown to correlate with increased eosinophils in blood, bronchoalveolar lavage fluid and sputum, suggesting that FENO reflects eosinophilic inflammation [2]. However, asthma is not a single disease and at least three adult phenotypes of airway inflammation have been identified on the basis of predominant eosinophilic, neutrophilic, or pauci-granulocitic cellular pattern [3].

Even though FENO is increased in children with allergic asthma [4], the obtained levels cannot discriminate among school children with non-allergic asthma. Furthermore, FENO can be elevated in patients who are atopic and not asthmatic. Levels of FENO appear increased in asthmatics with pollen allergy during the season even though there may be an absence of symptoms and normal lung function [5].

It had been postulated that tracking FENO may be helpful in managing asthma, as it improves after steroid treatment and may predict exacerbations in pollen sensitive asthma. However, it has been shown not to correlate with symptoms, and a meta-analysis [6] of three pediatric studies showed that FENO-guided treatment did not improve asthma outcomes.
The goal of long-term asthma treatment is to reduce airway inflammation and control symptoms. In this month's journal, Raj, et al. [7] studied children with asthma to investigate whether FENO could predict an acute exacerbation or its severity. This paper addresses a very important issue in current asthma management, as FENO has been proposed as a biomarker, correlating well with levels of eosinophilic airway inflammation. Some papers have suggested its use for guiding pharmacotherapy. In everyday practice, however, it seems to be very helpful for some patients, while it does not correlate with clinical symptoms and lung function in others.

The authors studied 243 asthmatic children (mean age 99 months), with an average duration of follow up of 434 days (range 84 to 825 days). Patients were reviewed every 3 months and underwent spirometry, FENO, pulmonary symptom scores, skin prick tests to aeroallergens and blood eosinophil counts were measured. Although FENO levels increased during an exacerbation, the authors were unable to find a particular cut-off which could help in either diagnosing an acute asthma exacerbation or predicting its severity in children.

So, should the results of this and other recently published studies [8,9] discourage the clinician from using FENO as a routine marker for guiding management in this age group? If asthma symptoms and inflammation were concordant, measuring FENO would not likely be useful. It is only when they are discordant - that is inflammation is disproportionately greater than symptoms, or vice-versa - measuring FENO may prove beneficial. Clearly, measuring FENO or other inflammatory biomarkers is no substitute for doing the basics of asthma management correctly; as often, simple measures can improve symptoms and avoid escalation of treatment. Adherence must be optimized, co-morbidities treated, allergen load reduced to a minimum and inhaler technique regularly checked. 
Certainly more studies will need to be done in this area of pediatric asthma. FENO may remain a useful marker for assessing patients at the time of diagnosis and also to help monitor the level of asthma control of individual patients in clinical practice.

\section{REFERENCES}

1. Kharatonov SA, Barnes PJ. Exhaled markers of pulmonary disease. Am J Respir Crit Care Med. 2001;163:16931722.

2. Jouaville LF, Annesi-Maesano I, Nguyen LT, Bocage AS, Bedu M, Caillaud D. Interrelationship among asthma, atopy, rhinitis and exhaled nitric oxide in a populationbased sample of children. Clin Exp Allergy. 2003;33: 1506-11.

3. Wenzel SE. Asthma: defining of the persistent adult phenotypes. Lancet. 2006;368:804-13.

4. Frank TL, Adisesh A, Pickering AC, Morrison JF, Wright $\mathrm{T}$, Francis $\mathrm{H}$, et al. Relationship between exhaled nitric oxide and childhood asthma. Am J Respir Crit Care Med. 1998;158:1032-6.
5. Vahlkvist S, Sinding M, Skamstrup K, Bisgaard H. Daily home measurements of exhaled nitric oxide in asthmatic children during natural birch pollen exposure. J Allergy Clin Immunol. 2006; 117:1272-6.

6. Petsky HL, Cates CJ, Lasserson TJ, Li AM, Turner C, Kynaston JA, et al. A systematic review and metaanalysis: tailoring asthma treatment on eosinophilic markers (exhaled nitric oxide or sputum eosinophils). Thorax. 2012;67:199-208.

7. Raj D, Lodha R, Mukherjee A, Sethi T, Agrawal A, Kabra SK. Fractional exhaled nitric oxide in children with acute exacerbation of asthma. Indian Pediatr. 2013;51:105-11.

8. de Jongste JC, Carraro S, Hop WC, the CHARISM Study Group, Baraldi E. Daily telemonitoring of exhaled nitric oxide and symptoms in the treatment of childhood asthma. Am J Respir Crit Care Med. 2009;179:93-7.

9. Szefler SJ, Mitchell H, Sorkness CA, Gergen PT, O'Connor GT, Morgan WJ, et al. Management of asthma based on exhaled nitric oxide in addition to guideline-based treatment for inner-city adolescents and young adults: a randomised controlled trial. Lancet. 2008;372:1065-72.

\title{
Exhaled Nitric Oxide in Children with Asthma
}

\author{
RESPIRATORYCARE NURSE'S PERSPECTIVE \\ Helen Petsky \\ Queensland Children's Medical Research Institute, Queensland University of Technology, Royal Children's Hospital, Herston, \\ Queensland, Australia.helenpetsky@gmail.com
}

A sthma is one of the most common chronic diseases in children. Acute exacerbations are not uncommon in children with asthma and many are hospitalized. Not surprisingly, hospitalizations for asthma are very common, accounting for $12-21 \%$ of hospitalizations worldwide [1]. Thus prevention of exacerbations, particularly severe ones, is one goal of good asthma management. The second component in asthma management is monitoring of asthma control, by both subjective and objective measures [2-4]. Subjective measures usually involve a series of questions used for clinical assessment, diary cards and quality of life (QoL) questionnaires. Traditional objective methods include peak flow meters, spirometry and degree of airway hyperresponsiveness (AHR). Newer and arguably more sensitive methods include measurement of airway inflammation such as airway cellularity in induced sputum or fractional exhaled nitric oxide (FENO). In asthma, inflammation can be eosinophilic or non-eosinophilic. In patients with eosinophilic inflammation, the use of inhaled corticosteroids (ICS) reduces exacerbations and improves symptoms and asthma control. FENO correlates with other markers of asthma eg. eosinophilia in induced sputum [5] and bronchial reactivity in non-steroid treated subjects [6].

The first study to use FENO as a biomarker was published by Dupont and colleagues [6] in 1998. They measured FENO in steroid treated and untreated adults with mild asthma. These levels correlated with the degree of AHR as measured by the dose of histamine required to produce a $20 \%$ decrease in forced expiratory volume in first second $\left(\mathrm{FEV}_{1}\right)$. The authors concluded that FENO levels reflect AHR in patients with mild asthma who were steroid naïve. The adults who were treated with ICS had similar FENO levels as the healthy controls [6].

As asthma in adults is not identical to that in children, data relating FENO and asthma control specific to children is important. There are many studies that have related FENO with various clinical aspects of asthma in children. Byrnes, et al. [7] recruited 39 children as 
controls from local school and 31 children with a clinical diagnosis of asthma. The aims of the study were to determine if FENO could be measured in children, and whether the pattern seen in adults with asthma versus adult controls is observed in children with asthma on bronchodilators only, had the highest FENO level. The FENO levels for children with asthma on regular ICS was not statistically different from the control children [7]. As FENO relates to airway eosinophilic inflammation, FENO as a biomarker can be potentially used in children with asthma to monitor the response to (and hence adjust) asthma medications, verify the adherence to ICS, and predict upcoming asthma exacerbations. Based on data above that showed the potential value of using FENO in improving asthma outcomes, the research undertaken by Raj, et al. [8] has provided further evidence that FENO levels increase during an asthma exacerbation but may not provide any clinical significance.

A Cochrane review [9] assessing the efficacy of tailoring asthma interventions based on FENO levels versus clinical symptoms for improving asthma related outcomes has been undertaken. The review includes 6 studies ( 2 adult studies and 4 involving children or adolescents). These studies differed in definition of asthma exacerbations, FENO cut-off levels used to determine adjustment of medications, type of therapy adjustment and the duration of studies. In the metaanalysis, there was no significant difference between groups for the primary outcome of asthma exacerbations, or for other outcomes (clinical symptoms, FENO level and spirometry). In post-hoc analysis, a significant reduction in mean final daily dose inhaled corticosteroid per adult was found in the group where treatment was based on FENO in comparison to clinical symptoms, (mean difference $-450 \mathrm{mcg}$; $95 \%$ CI -677 to -223 mcg budesonide equivalent/day). However, the total amount of inhaled corticosteroid used in one of the adult studies was $11 \%$ greater in the FENO arm. In contrast, in the pediatric studies, there was a significant increase in inhaled corticosteroid dose in the FENO strategy arm (mean difference of $140 \mathrm{mcg}$; 95\% CI 29 to $251 \mathrm{mcg}$ budesonide equivalent/day). These results have limited applicability, the most significant issue was that none of the six included studies considered presence or severity of atopy in their algorithm of management although some but not all subjects were atopic. This is important because atopy influences FENO levels regardless of the presence of asthma.

Funding: None; Competing interest: None stated.

\section{REFERENCES}

1. Gupta R, Anderson HR, Strachan DP, Maier W, Watson L. International trends in admissions and drug sales for asthma. Int J Tuberc Lung Dis. 2006;10:138-45.

2. National Asthma Council Australia. Asthma Management Handbook 2006. Melbourne, 2006. Available from: http:// www.nationalasthma.org.au/handbook. Accessed December 10, 2013.

3. Global Initiative for Asthma. Pocket Guide for Asthma Management and Prevention. Available from: http:// www.ginasthma.org/local/uploads/files/GINA_Pocket 2013 May15.pdf. Accessed December 10, 2013.

4. Scottish Intercollegiate Guideline Network. British Guideline on the Management of Asthma: A National Clinical Guideline. Consultation Draft 2.0 December 2013. Available from: http://www.brit-thoracic.org.uk/Portals/ 0/Guidelines/AsthmaGuidelines/Asthma\%20consultation \%20draft\%20ver\%202.0\%20-\%20041213.pdf. Accessed December 10, 2013.

5. Jatakanon A, Lim S, Kharitonov SA, Chung KF, Barnes PJ. Correlation between exhaled nitric oxide, sputum eosinophils, and methacholine responsiveness in patients with mild asthma. Thorax. 1998;53:91-5.

6. Dupont LJ, Rochette F, Demedts MG, Verleden GM. Exhaled nitric oxide correlates with airway hyperresponsiveness in steroid-naive patients with mild asthma. Am J Respir Crit Care Med. 1998;157:894-8.

7. Byrnes CA, Dinarevic S, Shinebourne EA, Barnes PJ, Bush A. Exhaled nitric oxide measurements in normal and asthmatic children. Pediatr Pulmonol. 1997;24:312-8.

8. Raj D, Lodha R, Mukherjee A, Sethi T, Agrawal A, Kabra SK. Fractional exhaled nitric oxide in children with acute exacerbation of asthma. Indian Pediatr. 2013;51:105-11.

9. Petsky HL, Cates CJ, Li AM, Kynaston JA, Turner C, Chang AB. Tailored interventions based on exhaled nitric oxide versus clinical symptoms for asthma in children and adults. Cochrane Database Syst Rev. 2009;4:CD006340. 